\title{
THE BEHAVIOR OF HIGH-BOILING MINERAL OILS ON HEATING IN THE AIR
}

\author{
By C. E. Waters
}

\section{HISTORICAL}

In a paper published some months ago, Schreiber ${ }^{1}$ gives the results obtained when different cylinder and compressor oils were heated in a specially constructed air bath through which a current of air, carbon dioxide, or steam could be passed. The duration of the tests varied from 16 to 24 hours, and the temperature from $200^{\circ}$ to $280^{\circ}$. The percentages of asphaltic material in the oil before and after heating were determined. The results showed that the amount of such material insoluble in benzine and in alcohol-ether greatly increased in the presence of air and of carbon dioxide, but was practically unchanged when the oil was heated in steam. Some of the oils became greatly thickened or covered with a gummy surface skin, while others withstood the test remarkably well, thus demonstrating their fitness for use in steam cylinders. A problem of a similar nature having been submitted to this Bureau, the present writer adopted, without knowledge of Schreiber's work, a method similar to his, but differing sufficiently from it in its details that the publication of this paper seems justifiable, especially as the oils to be tested were intended for use in gas engines. Without going immediately into details, it may be said that both Schreiber and the author heated the oils to a considerably higher temperature than that adopted by most of the previous workers.

A summary of the more important work done along this line may not be out of place. 
In $\mathrm{I} 884$, Fox $^{2}$ investigated lubricating oils by a modification of a method described shortly before by Livache ${ }^{3}$ for the recognition of drying oils. The oils were heated in sealed tubes with precipitated lead and the amount of oxygen absorbed was measured.

Zaloziccki ${ }^{4}$ passed air through heated mineral oils and found acetic acid in the water formed by oxidation. The distillate had the odor of other members of the series of fatty acids. Engler and Bock, ${ }^{5}$ in addition to naphthenic acids, observed the formation of butyric and other fatty acids by blowing air through hot, neutral petroleum.

Charitschkow ${ }^{6}$ obtained two series of acid oxidation products, one from the alkali sludge, the other by oxidizing petroleum by air in the presence of alkali at $150^{\circ}$. The latter series he called later " "polynaphthene," or "asphaltogenic" acids.

In spite of conflicting statements, ${ }^{8}$ it is well established that mineral oils oxidize when raised to moderately elevated temperatures in the air. They may oxidize even at ordinary temperatures when exposed to sunlight, especially in the presence of alkalies. The writer has discussed this subject in another paper, in which it is shown that water and carbon dioxide are formed, in addition to acids that remain in the oil. ${ }^{9}$

Another phenomenon closely connected with the formation of acids is the production of resinous or asphaltic substances when oils are heated in the air. This and the cracking of the oils are both probably concerned in the "carbonization" of gas-engine cylinder oils. The cracking of mineral oils has, of course, been known for several decades, but a knowledge of the other chemical changes mentioned is not so widespread, although no argument is needed to convince one of its importance, especially to users of gas engines.

${ }^{2}$ Zs. anal. Chem., 23, p. 434, 1884.

${ }^{3}$ Mon. Sci., [3], 13, p. 299; Zs. anal. Chem., 23, p. 262, I884.

4 Zs. angew. Chem., pp. 4I6-4I9, I89I.

${ }^{5}$ Cf. Chem.-Ztg., 16, p. 592, I892.

${ }^{6}$ Petroleum, 2, p. 480, 1907; J. Soc. Chem. Ind., 26, p. $402,1907$.

${ }^{7}$ Chem.-Ztg., 33, p. Ir65, Ig09.

${ }^{8}$ Hirsch: Chem.-Ztg., 19, p. 4I, 1895.

${ }^{9}$ 'This Bulletin, 7, p. 227. 
In 1894 Holde ${ }^{10}$ determined the asphalt content of certain darkcolored mineral lubricating oils before and after heating to $100^{\circ}$ for ro hours. He found that oils with little or no asphalt originally remained liquid; those with 1.3 to 2.3 per cent became thick and sticky; those with 5 to 6 per cent were changed to a thick resin-like mass. He showed later ${ }^{11}$ that the gumming is due not only to a concentration of the asphalt as the oil evaporates, but also to a partial oxidation of the oil.

Adiasiewitsch ${ }^{12}$ described the preparation of resinous products by blowing "deoxygenated air" through the residue in the petroleum still, the temperature varying from $150^{\circ}$ to $200^{\circ}$. The resultant "resins" varied from thick liquids to solid, asphaltlike masses, and all were soluble in petroleum distillates.

Mabery and Byerley ${ }^{13}$ also made asphalt from heavy petroleum residues by blowing air through the mass for four or five days, the temperature being kept at $60^{\circ} \mathrm{F}$. Culmer ${ }^{14}$ obtained similar results in 40 hours at $193^{\circ}$.

In this connection may be mentioned the belief of Meyerheim ${ }^{15}$ that the increase in the asphalt content with time is due to a polymerization of the oil or to a change of the asphalt from its original colloid state to the insoluble form. Radium emanation caused no increase in the amount.

Richardson ${ }^{16}$ and Hanson studied the change in viscosity of oils heated in thin layers at temperatures varying from $100^{\circ}$ to $201^{\circ}$. In an atmosphere of superheated steam changes exactly similar to those in air were produced. Worrall and Southcombe, ${ }^{17}$ however, state that in cylinders heated as high as $750^{\circ} \mathrm{F}$. steam causes no chemical change in the oil. The horny or granular deposit at times found in cylinders is $\mathrm{Fe}_{2} \mathrm{O}_{3}$ or $\mathrm{Fe}_{3} \mathrm{O}_{4}$ cemented together by oil.

${ }^{10}$ Mitth. kgl. techn. Versuchsanst., 11, pp. 26I-272; J. Soc. Chem. Ind., 13, p. 668; 1894 .

11 Ibid., 13, pp. I74-I96; I895.

${ }^{12}$ See abstract in J. Soc. Chem. Ind., 15, p. 346; 1896.

${ }_{13}$ Amer. Chem. J., 18, pp. I41-150; 1896.

${ }_{14}$ Rev. Prod. Chim., 2, p. 356; J. Soc. Chem. Ind., 19, p. 525; Igo0.

${ }^{15}$ Chem.-Ztg., 34, p. 454; igro.

${ }_{16} \mathrm{~J}$. Soc. Chem. Ind., 24, pp. 3I5-3I9; 1905.

17 Ibid., 27, p. 308; I908. 
Kissling ${ }^{18}$ determined the "resinification number" of oils. The amount of material precipitated by petroleum ether was determined after the oils had been heated to $125^{\circ}$ to $135^{\circ}$ for $\mathrm{r} 2$ hours on each of five successive days. The results showed that less insoluble matter is formed in the better refined oils. The percentages of insoluble formed may vary a great deal more than the iodine and Maumené values. Kissling later ${ }^{10}$ published a somewhat modified method, according to which the oil is treated with alcoholic soda, which extracts the "resin" originally present or formed by heating. The "coke-like" matter is thrown out by benzine. The oils are heated to $150^{\circ}$ to $250^{\circ}$.

Letschford ${ }^{20}$ studied the oxidation of spindle oils when heated to $95^{\circ}$ to $98^{\circ}$ for 75 hours. The ratio of the product insoluble in petroleum ether to the original oil was called the "acid coefficient."

It is of fundamental importance to have a satisfactory method for determining the asphalt in oils. One method that has been tried is to determine the diminution in volume when the oil is shaken with concentrated sulphuric acid and then allowed to stand. This has been found to be unreliable. ${ }^{21}$

Distilling off the oil by means of superheated steam has also been recommended. ${ }^{22}$ But practically the only method used is the precipitation by means of benzine or other light petroleum distillate. This is based on an observation by Bender. ${ }^{23}$ It has been found that the amount of insoluble matter precipitated depends on the boiling-point limits of the benzine used. Hence the necessity for a carefully specified "normal" benzine. ${ }^{24}$ Still later, Kissling ${ }^{25}$ showed that benzines from different sources, though they may boil between the same limits, are not to be used

\footnotetext{
${ }^{18}$ Chem.-Ztg., 30, pp. 932-933; 1906.

${ }^{19}$ Ibid., 31, p. 328; I907; 32, p. 938 ; 1908.

${ }^{20}$ Seifensiederztg., 1908, No. 2 ; Zs. angew. Chem., 22, p. 1066; rgog.

${ }^{21}$ Aisinmann: Dingl. Pol. J., 294, pp. 65-68; 1894; J. Soc. Chem. Ind., 14, p. 282. Charitschkow: Petroleum, 2, pp. 99-I0I; I906; J. Soc. Chem. Ind., 25, p. II40; 1906.

${ }^{22}$ Lecocq: Bull. Soc. Chim. Belg., 22, pp. 8I-87; Chem. Abstr., 2, p. I880; rgo8.

${ }^{23}$ Mitth. kgl. techn. Versuchsanst., I890, 31 I -316 ; J. Soc. Chem. Ind., 10, p. 354 ; r8gr.

${ }^{24}$ Holde: Mitth. kgl. Materialprüfungsamt, 27, p. x43; 1909.

${ }^{25}$ Chem.-Ztg., 33, p. I203; I909.
} 
indiscriminately if the results obtained by different chemists are to be compared. Thus, a sample of Kahlbaum's "normal benzine" gave lower values than benzine from Pennsylvania petroleum. Benzine from an Indian petroleum gave higher values than either of the preceding.

\section{EXPERIMENTAL}

The four oils submitted to this Bureau had the following constants:

\begin{tabular}{|c|c|c|c|c|}
\hline Sample.. & 1 & 2 & 3 & 4 \\
\hline Flash point........ & $140^{\circ}$ & $224^{\circ}$ & $142^{\circ}$ & $142^{\circ}$ \\
\hline Engler no. at $50^{\circ} \ldots$ & 3.3 & 3.4 & 3.6 & 2.9 \\
\hline Engler no. at $100^{\circ} \ldots \ldots \ldots$ & 1.4 & 1.4 & 1.5 & 1.4 \\
\hline Acidity (per cent oleic acid). & 0.033 & 0.024 & 0.023 & 0.025 \\
\hline 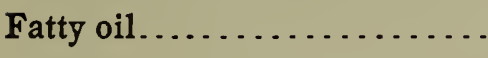 & None. & None. & None. & Irone. \\
\hline
\end{tabular}

In the preliminary experiments two mineral oils that had been on hand for a considerable time were used to test the method. Ten-gram samples were heated one at a time in matched Erlenmeyer flasks of I5O-cc capacity. The flasks rested on a small tripod of glass rod on the bottom of a large iron crucible, which was covered with a brass plate having a large hole through which the upper two-fifths of the flask projected. The bath was kept at $250^{\circ}$ for one and one-half hours, and at the same time a fairly rapid current of air was passed in through a tube of Jena combustion glass bent at right angles at one end. Near the bend was a closely fitting sheath of brass tubing, under which was a fishtail burner for preheating the air. Concordant results could not be obtained on account of the impossibility of accurately regulating the two flames and air current, all three varying from time to time during the day.

A cubical air bath of sheet copper was then constructed. Openings were cut in the movable cover so that four flasks could be suspended by their necks. The sides and top of the bath were covered with sheet asbestos. A "rose" top was used on the burner, and the heating further equalized by means of a circular 
sheet of brass, resting on a glass tripod about $2 \mathrm{~cm}$ high, on the bottom of the bath. The temperature was kept constant within $2^{\circ}$ or $3^{\circ}$ by means of a thermoregulator. There was nothing to prevent perfect freedom of diffusion of oil vapors and air at the mouths of the flasks.

Four Io-gram samples of the two trial oils were heated to $250^{\circ}$ for three hours. The losses by evaporation did not agree very closely. To determine the amount of material insoluble in petroleum ether, $50 \mathrm{cc}$ of the solvent were placed in each flask, which was then corked, shaken gently, and let stand overnight. The insoluble matter, except the coating on the walls of the flasks, was then filtered off in Gooch crucibles containing disks of S. \& S. No. 589 , Blue Ribbon filter paper, covered with a thick felt of fine asbestos. The results are given in the table:

\begin{tabular}{r|c|c|c|c|c|c|c|c}
\hline Sample ................... & A & A & A & A & B & B & B & B \\
\cline { 1 - 7 } Flask...................... & (a) & (b) & (c) & (d) & (a) & (b) & (c) & (d) \\
Per cent evaporation.......... & 5.00 & 4.50 & 6.20 & 7.90 & 9.44 & 7.35 & 9.29 & 15.92 \\
Per cent insoluble filtered off. & 0.55 & 0.48 & 0.51 & 0.55 & 0.34 & 0.42 & 0.40 & 0.37 \\
Per cent insoluble in flask.... & 0.10 & 0.25 & 0.15 & 0.05 & 0.09 & 0.37 & 0.39 & 0.08 \\
Total insoluble............... & 0.65 & 0.73 & 0.66 & 0.60 & 0.43 & 0.79 & 0.79 & 0.45 \\
\hline
\end{tabular}

Duplicate tests were then made with the four samples of oil submitted to us for examination. The results follow:

\begin{tabular}{|c|c|c|c|c|c|c|c|c|}
\hline Sample. & 1 & 1 & 2 & 2 & 3 & 3 & 4 & 4 \\
\hline Flasi. & (a) & (b) & (c) & (d) & (a) & (b) & (c) & (d) \\
\hline Per cent evaporation... & 9.90 & 9.40 & 10.75 & 14.45 & 7.60 & 6.50 & 13.35 & 16.10 \\
\hline Per cent insoluble filtered off & 0.87 & 0.91 & 0.40 & 0.47 & 0.08 & 0.12 & 0.84 & 0.60 \\
\hline Per cent insoluble in flask.. & 0.30 & 1.25 & 1.40 & 0.70 & 0.10 & 0.20 & 0.85 & 0.40 \\
\hline Total insoluble..... & 1.17 & 2.16 & 1.80 & 1.17 & 0.18 & 0.32 & 1.69 & 1.00 \\
\hline
\end{tabular}

An inspection of the results will show that the chief cause of the irregularities, when duplicates are run, is the insoluble matter remaining in the flask. This is a dark brown, varnish-like coating which does not dissolve in petroleum ether. Even when heated on the steam bath for two or three days with chromic acid mixture, 
only part of it is removed, but soaking with alcoholic soda for two or three hours so loosens it that it may be rinsed out easily.

Duplicate determinations of the amount of flocculent insoluble matter filtered off agree very well, except the results on No. 4 .

The flasks were not placed in the bath in any regular order, but in three of the heatings flasks $(a)$ and $(d)$ gave low results on the coating or "varnish" (oils A, B, I, and 2). This does not hold for oils 3 and 4 , but even here flask (a) showed less varnish than (b) and flask $(d)$ less than $(c)$.

It may be mentioned parenthetically that oil No. 3 was recommended by us as the best of the four. We have since learned that one of the other oils was first given a trial by the company for which the test was made. It proved to be entirely unsuitable, while No. 3 , which was then used, has been satisfactory.

Variations in the condition of the walls of the flasks, all of which had been used for other purposes, seemed to be a possible explanation of the discrepancies in the amounts of "varnish" found. Accordingly, four new Jena flasks were carefully cleaned and used to obtain the following results. Only oil B was used.

\begin{tabular}{|c|c|c|c|c|}
\hline Flask $\ldots \ldots \ldots \ldots \ldots \ldots \ldots \ldots \ldots \ldots \ldots \ldots \ldots \ldots \ldots \ldots$ & $\left(a^{\prime}\right)$ & $\left(b^{\prime}\right)$ & $\left(c^{\prime}\right)$ & $\left(d^{\prime}\right)$ \\
\hline Per cent evaporation................... & 21.55 & 22.60 & 23.15 & 25.40 \\
\hline Per cent insoluble filtered off.. & 0.32 & 0.32 & 0.44 & 0.61 \\
\hline Per cent insoluble in flask... & 0.17 & 0.08 & 0.50 & 0.92 \\
\hline Total insoluble..... & 0.49 & 0.40 & 0.94 & 1.53 \\
\hline
\end{tabular}

A series of results was also obtained with a new set of flasks of "resistance" glass. Oil B was again used.

\begin{tabular}{|c|c|c|c|c|}
\hline 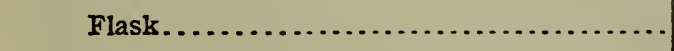 & $\left(a^{\prime \prime}\right)$ & $\left(b^{\prime \prime}\right)$ & $\left(\mathbf{c}^{\prime \prime}\right)$ & $\left(d^{\prime \prime}\right)$ \\
\hline Per cent evaporation.......... & 10.35 & 11.55 & 15.80 & 16.45 \\
\hline Per cent insoluble filtered off. & 0.33 & 0.44 & 0.25 & 0.23 \\
\hline Per cent insoluble in flask.. & 0.45 & 0.82 & 0.29 & 0.11 \\
\hline Total insoluble............. & 0.78 & 1.26 & 0.54 & 0.34 \\
\hline
\end{tabular}

A consideration of all the figures obtained with oil B shows that while the "insoluble filtered off" varies from 0.23 to $0.6 \mathrm{I}$ per cent, 
nine of the twelve results lie within the limits 0.32 and 0.44 per cent. The average of these is 0.37 per cent, and the average for all twelve is $0.371 / 4$ per cent.

\begin{tabular}{r|c|c|c|c}
\hline Flask................................. & A & B & C & D \\
\hline Per cent varnish, first heat............. & 0.11 & 0.30 & 1.20 & 0.48 \\
Increase in varnish, second heat........ & 0.82 & 1.94 & 1.03 & 0.46 \\
Per cent insoluble, first heat........... & 0.26 & 0.30 & 0.55 & 0.32 \\
Per cent insoluble, second heat......... & 0.50 & 0.40 & 0.57 & 0.64 \\
\hline
\end{tabular}

Another interesting series of results was obtained by heating two lots of oil B in the resistance glass flasks. For the second heating the varnish was not removed, the flasks being thoroughly washed out with petroleum ether before a new lot of oil was introduced.

At the second heating the amounts of both varnish and insoluble are greater than at the first, except in one instance.

It is unfortunate that Schreiber does not publish any duplicate determinations on the same oil, nor is he able, with his apparatus, to make any distinction between the "varnish" and the flocculent, insoluble matter. His statement that the formation of "asphalt" depends on oxidation we can fully confirm, for in some of the earliest experiments we heated the oil in glass-stoppered bottles and found only traces of insoluble matter and no varnish at all.

In order to further test the possibility of variations being caused by the nature of the walls of the containing vessels, glass tubes of $20 \mathrm{~mm}$ bore and $10.5 \mathrm{~cm}$ long were made. Tubes of the same inside dimensions were made of ordinary brass, cold-rolled steel, and also from a steel containing 0.8 per cent carbon, a vanadium steel, a chrome-vanadium steel, and cast iron. These tubes were made in pairs. One of the vanadium steel tubes leaked so badly that it could not be used. Both of the cast-iron tubes had fine pores through which a little oil escaped, but they became plugged up at the first heating. All of these tubes, except those of cold. rolled steel and brass, were made from the centers of the billets from which the standard samples issued from this Bureau were cut. Their size was necessarily limited and this had the disadvantage that only 5 grams of oil could be heated at a time, for when 25 
cc of ligroin were added after heating there was just enough space left to insert a cork safely. The metal tubes were made with flaring, knife-edge rims to diminish creeping of the oil when the insoluble was filtered off.

In every case the oil, after dilution with petroleum ether, was allowed to stand about 22 hours, it having been found that the precipitate was less apt to clog the filter than when a shorter time elapsed.

For the heatings in the different tubes three oils, designated as B, C, and D, were used. They had been kept for a long time in closed tin cans. The organic acidity, saponification number, and flash point were determined.

\begin{tabular}{|c|c|c|c|}
\hline Sample.. & B & C & $\mathbf{D}$ \\
\hline Organic acidity (as per cent oleic acid)... & 0.08 & 0.03 & 0.07 \\
\hline Fatty oil (approximate) $\ldots \ldots \ldots \ldots \ldots$ & None & None & 0.5 \\
\hline Flash point............. & $205^{\circ}$ & $195^{\circ}$ & $195^{\circ}$ \\
\hline
\end{tabular}

Oil B gave an incipient flash at $185^{\circ}$. The Pensky-Martens closed cup flash-point apparatus was used.

A complete series of heatings was run only with oil $\mathrm{B}$, this having been considered unnecessary with $\mathrm{C}$ and $\mathrm{D}$. The results are given below, expressed as percentages of insoluble matter and varnish.

GLASS TUBES

\begin{tabular}{r|c|c|c|c|c|c|c|c}
\hline Oil......................... & B & B & B & B & C & C & D & D \\
\hline Varnish...................... & 0.44 & 0.03 & 0.08 & 0.10 & 0.11 & 0.09 & 0.04 & 0.04 \\
Insoluble.................. & 0.10 & 0.07 & 0.08 & 0.05 & 0.10 & 0.08 & 0.07 & 0.09 \\
\hline
\end{tabular}

BRASS TUBES

\begin{tabular}{|c|c|c|c|c|c|c|c|c|}
\hline Oil.............. & $B$ & B & B & B & $\mathrm{c}$ & c & D & $\mathrm{D}$ \\
\hline Varnish & & & & & 0.02 & 0.03 & & \\
\hline Insoluble.. & 0.15 & 0.18 & 0.15 & 0.16 & 0.13 & 0.15 & 0.07 & 0.06 \\
\hline
\end{tabular}




\section{CAST-IRON TUBES}

\begin{tabular}{r|c|c|c|c|c|c}
\hline Oil........................ & B & B & C & C & D & D \\
\hline Varnish................... & 0.07 & 0.01 & Trace & Trace & Trace & Trace \\
Insoluble................. & 0.06 & 0.06 & 0.08 & 0.08 & 0.07 & 0.05 \\
\hline
\end{tabular}

CHROME-VANADIUM STEEL TUBES

\begin{tabular}{r|c|c|c|c|c|c}
\hline Oil........................ & B & B & B & B & C & C \\
\hline Varnish................... & 0.05 & 0.04 & 0.03 & 0.02 & Trace & 0.01 \\
Insoluble................. & 0.07 & 0.06 & 0.08 & 0.08 & 0.14 & 0.13 \\
\hline
\end{tabular}

In the remaining tubes only oil $\mathrm{B}$ was heated.

\begin{tabular}{|c|c|c|c|c|c|c|c|c|c|c|}
\hline \multirow{2}{*}{$\frac{\text { Tube.. }}{\text { Varnish... }}$} & \multicolumn{2}{|c|}{ Vanadium steel } & \multicolumn{4}{|c|}{ Cold-rolled steel } & \multicolumn{4}{|c|}{0.8 carbon steel } \\
\hline & 0.02 & 0.04 & 0.04 & 0.03 & 0.02 & Trace & 0.03 & 0.02 & 0.03 & 0.03 \\
\hline Insoluble. & 0.07 & 0.08 & 0.08 & 0.08 & 0.09 & 0.09 & 0.07 & 0.10 & 0.07 & 0.07 \\
\hline
\end{tabular}

The above results seem to show that the material of which the tubes are made exerts an influence upon the amount both of the varnish and the precipitate formed in the oil itself. The differences are not great, but neither are the actual amounts large, most likely because of the relatively small surface of oil exposed to the action of the air. This area was only $3.14 \mathrm{sq} \mathrm{cm}$, while only double the amount of oil in a flask exposed a surface about nine times as great. The most striking discrepancy in the results is that oil $\mathrm{D}$ yielded less insoluble in the brass tubes than in those of glass, while $\mathrm{B}$ and $\mathrm{C}$ gave much larger amounts in the brass tubes. The reason for this may be that $\mathrm{D}$ contained about 0.5 per cent of fatty oil, the others being straight mineral oils.

That the three oils show wider differences when heated in flasks is shown by the following figures obtained with resistance glass flasks. The percentages of evaporation, varnish and insoluble are given. 


\begin{tabular}{r|c|c|c|c|c|c|c|c|c|c|c|c}
\hline Oil............. & B & B & B & B & C & C & C & C & D & D & D & D \\
\hline Flask............ & (a) & (b) & (c) & (d) & (a) & (b') & (c) & (d) & (a) & (b') & (c) & (d) \\
\hline Evaporation........ & 19.00 & 19.03 & 19.95 & 15.08 & 17.15 & 25.75 & 13.05 & 15.77 & 23.93 & 22.83 & 13.42 & 19.32 \\
Varnish........... & 0.18 & 0.74 & 0.75 & 0.25 & 0.37 & 1.14 & 0.38 & 0.43 & 1.01 & 0.57 & 1.27 & 1.25 \\
Insoluble........... & 0.28 & 0.48 & 0.40 & 0.29 & 1.90 & 2.29 & 1.88 & 1.81 & 2.30 & 1.89 & 2.25 & 2.50 \\
\hline
\end{tabular}

Flask $\left(b^{\prime}\right)$, first used for oil $\mathrm{C}$ and subsequently for $\mathrm{D}$, replaced (b) in which $B$ was heated. It is curious that for one oil it gave high and for the other low results.

In our opinion the formation of "asphalt," or as we have called it, "insoluble," is due to partial oxidation of the oil rather than to polymerization or to concentration of the asphalt as the oil evaporates. As mentioned above, there was practically no formation of insoluble when the oil was heated to $200^{\circ}$ for three hours in stoppered bottles. When heated for the same length of time in flasks loosely covered with watch-glasses, there was opportunity for atmospheric oxygen to enter as rapidly as it was absorbed by the oil. At the same time the lack of perfect freedom of diffusion allowed the escape of only the more volatile constituents so that the change in weight was negligible. No varnish was formed, but the following percentages of insoluble were obtained: $0.47,0.5^{2}$, 0.38 , and 0.33 . Not enough of this oil was available for a test in the apparatus finally adopted.

Although the figures obtained by heating duplicate samples of the same oil side by side are often less concordant than could be desired, yet on the whole the method seems to be capable of yielding data of value; this in spite of differences caused by unequal heating, variations in the rate of interdiffusion of oil vapors and air and, apparently, obscure catalytic phenomena influenced by the nature of the material in which the oil is heated. At present the method can be used to compare a limited number of oils with one another. To make it of perfectly general application would require a standard apparatus of carefully specified dimensions and material. The petroleum ether used would also need to be of very definite composition. Observing these and other obvious precautions, the requirements of the case would be more than met, 
for in actual practice the conditions must vary considerably more than in a laboratory experiment.

It is not claimed by anyone who has worked along this line that the method does more than indicate what may be expected to happen when an oil is in actual use, or rather, which of two or more oils will behave least badly. But even a slight indication is of greater value than complete ignorance, and a laboratory test is more rational than placing implicit confidence in a dealer's statements.

It is our intention to go more fully into the question of standardization and also to study the effect of the addition of fatty oils and other substances to the mineral oils before heating.

WASHINGTON, December I4, I9IO. 